\title{
Conxuntura estatística do ámbito cultural. Xuño de 2020
}

DOI: $10.17075 /$ ceacx.2020

DOCUMENTOS DE TRABALLO

CCG

A crise sanitaria e as medidas decretadas polo Goberno central tiveron un impacto moi importante no ámbito cultural. A situación provocada pola declaración do estado de alarma en España por mor da pandemia sufrida afectou de forma xeneralizada a todos os sectores culturais en Galicia e no conxunto de España.

Tal e como adiantou o Observatorio da Cultura Galega', a situación de crise afectou ao emprego cultural, que descendeu un 5,5\%, 2,3 puntos porcentuais máis que o conxunto do mercado laboral no mes de marzo. As ramas de actividade máis afectadas foron as de cinematografía, de vídeo e de programas de televisión, gravación de son e edición musical, seguidas das actividades de creación, artísticas e espectáculos, que, de feito, se atopan entre as máis afectadas de todas as que compoñen a economía galega. Por réximes de actividade, vense moito máis afectadas as persoas que traballan no réxime xeral ca no de autónomos, posiblemente pola posibilidade que teñen estes últimos de acceder á prestación extraordinaria por ce-

${ }^{1}$ http://consellodacultura.gal/publicacion.php?id=4361
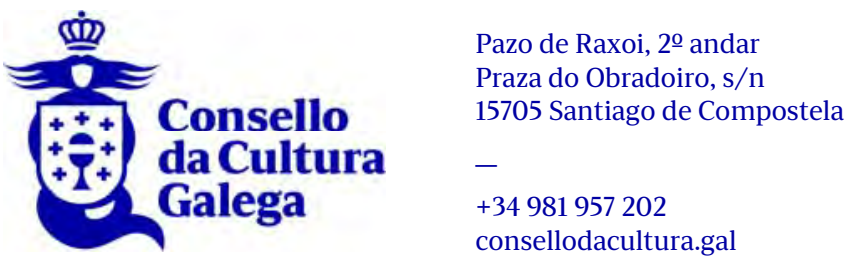
samento de actividade. Comparado con outros sectores, o da cultura perdeu proporcionalmente máis cotizacións que o conxunto dos servizos, a industria e o sector primario. O descenso só é equiparable ao producido na construción. En comparación co total do sector cultural de España, o descenso foi un pouco menor en Galicia, cunha diferenza dun punto porcentual. Tamén hai que ter en conta que existen unhas debilidades coñecidas do sector, como a temporalidade, o pequeno tamaño das empresas culturais e a alta incidencia de traballadores/as autónomos/as.

O Consello da Cultura Galega publicou recentemente varios documentos de traballo sectoriais sobre o estado da cultura galega perante a crise da COVID-19.

Concretamente no sector editorial ${ }^{2}$, as consecuencias foron moi negativas por mor da caída do consumo privado de libros e da actividade editorial e comercial das librarías, feiras do libro e campañas de promoción de libros de texto. Ademais, esta situación coincide nunha época de fortes vendas e presentación de novidades editoriais, que tiveron que anularse polo peche dos negocios e empresas editoriais. Como consecuencia disto, moitas pequenas editoriais, librarías e outros negocios asociados ao mundo editorial, como tradutores, maquetistas, artes gráficas etc., vense abocados a un posible peche definitivo por non poder asumir as perdas derivadas da paralización da súa actividade económica durante tres meses. Ademais das consecuencias económicas, pódense producir cambios na forma da distribución e consumo de libros, xa que a promoción de libros dixitais pode ser prexudicial para o sector debido á fenda dixital entre a poboación galega e a posibilidade de incremento da pirataría.

En canto á música, a crise sanitaria tivo un forte impacto no sector, con graves consecuencias económicas ${ }^{3}$. As medidas de prevención de contaxios, distanciamento social e limitación de afluencia de público decretadas polo Goberno afectan de xeito importante á súa actividade, cuxo obxectivo principal é precisamente a socialización. Este impacto económico trae consigo serias consecuencias laborais, por mor fundamentalmente da precariedade estrutural que sofre a música popular dende hai anos. Os

\footnotetext{
${ }^{2}$ http://consellodacultura.gal/mediateca/extras/CCG_2020_O-sector-do-libro-galegoperante-a-crise-da-COVID-19.pdf

${ }^{3}$ http://consellodacultura.gal/mediateca/extras/CCG_2020_O-sector-da-musicapopular-en-Galicia-perante-a-crise-da-COVID-19.pdf
} 
axentes do sector musical reivindican unha política que fomente unha industria con maior capacidade e fortaleza de cara ao futuro para enfrontarse a períodos críticos como o actual e solicitan: regulación laboral, sistema educativo con formación pública regrada, marco fiscal de tributación adaptado á súa singularidade, fomento do tecido produtivo a través de proxectos de colaboración, dotación de fondos para a creación dos artistas e estímulo de actividades culturais locais. A estratexia da Xunta de Galicia de fortalecer o vindeiro Xacobeo percíbese, en xeral, como unha oportunidade para canalizar axudas para empresas e artistas galegos, pero tamén como un acicate para o turismo e a cultura, aínda que tamén se detectan voces críticas. Non obstante, todos coinciden na conveniencia de ofrecer unha proposta musical atractiva que protexa o patrimonio cultural propio, sen pensar en grandes estrelas do panorama internacional, e apostan por desenvolver, a partir dunha fase de rescate e un plan de recuperación, un gran pacto de todo o sector da música, con conexións nacionais e internacionais, para incentivar o desenvolvemento económico e social nos vindeiros anos.

O presente documento de traballo ofrece información sobre todos os indicadores estatísticos dispoñibles sobre o ámbito cultural ata o momento da súa publicación. En primeiro lugar, analízase a situación económica do sector dende comezos do ano 2020 ata a actualidade no que respecta á creación de empresas a través da explotación Boletín Oficial do Rexistro Mercantil (BORME), os efectos desta crise sanitaria no emprego cultural a través dos datos da Enquisa de Poboación Activa (EPA), das afiliacións á Seguridade Social e dos expedientes de regulación temporal de emprego (ERTE). Así mesmo, analízanse as consecuencias desta situación de crise no consumo e comercio de produtos culturais a través dos datos de comercio exterior e intracomunitario de produtos culturais, da evolución do IPC e da confianza dos consumidores. Por último, examínase a situación do sector da cultura nas contas económicas de Galicia e faise unha prospección baseada nas realizadas para o conxunto da economía galega. Moitos indicadores que se analizan ao longo deste documento de traballo son do primeiro trimestre, polo que o impacto está limitado á segunda quincena de marzo. Cando foi posible, incluíronse datos de abril e maio.

\section{Creación de empresas}


A explotación do Boletín Oficial do Rexistro Mercantil (BORME) é unha operación estatística que elabora o Instituto Galego de Estatística (IGE) con carácter mensual. O obxectivo desta operación é medir a demografía das sociedades mercantís en Galicia e ofrece información sobre os seguintes aspectos:

- As empresas creadas, as que amplían e reducen capital e as que desenvolven dividendos pasivos.

- Información sobre as empresas en situación concursal e as quebras, disolucións, extincións e transformación de sociedades ocorridas no mes de estudos.

- Información sobre o número de socios fundadores das sociedades constituídas cada mes, así como da súa distribución por sexo.

A explotación desta fonte estatística para este informe ten como obxectivo coñecer o número de sociedades mercantís constituídas durante os meses de xaneiro a maio de 2020 e estudar a posible incidencia da crise sanitaria da COVID-19 na creación de empresas culturais durante este período en clave comparativa con respecto ao ano anterior.

Para determinar o número de empresas culturais creadas en Galicia tivéronse en conta os CNAE 2009 específicos das actividades culturais, que son os seguintes:

18. Artes gráficas e reprodución de soportes gravados.

58. Edición.

59. Actividades cinematográficas, de vídeo e de programas de televisión, gravación de son e edición musical.

60. Actividades de programación e emisión de radio e televisión.

73. Publicidade e estudos de mercado. 
90. Actividades de creación, artísticas e espectáculos.

91. Actividades de bibliotecas, arquivos, museos e outras actividades culturais.

Durante o período que abrangue xaneiro a maio de 2020 creáronse en Galicia 44 empresas culturais, das que 16 foron de publicidade e estudos de mercado e 11 foron das que realizan actividades cinematográficas, de vídeo e de programas de televisión, gravación de son e edición musical, seguido das de actividades de creación, artísticas e espectáculos (10). $O$ resto de actividades teñen unha incidencia menor. Pola contra, non se creou ningunha empresa de actividades de programación e emisión de radio e televisión.

Por provincias, foi na da Coruña onde se crearon máis empresas neste período, seguida da de Pontevedra.

Por meses, en marzo foi cando se crearon máis empresas pero, como contraste, os meses de abril e maio foron os que rexistraron o menor número de altas de empresas. Concretamente, en abril creáronse dúas empresas e en maio cinco. A continuación pódese ver a evolución: 


\section{Evolución do número de empresas culturais creadas (xaneiro-maio 2020)}

18

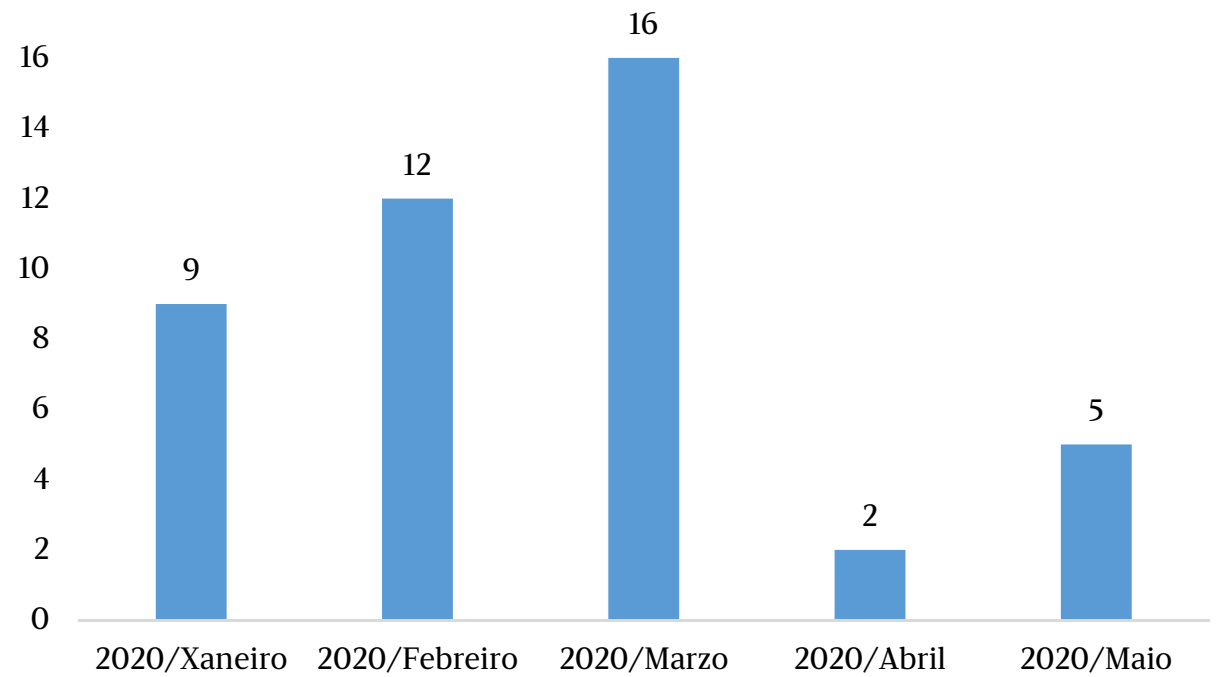

Fonte: IGE. Explotación do Boletín Oficial do Rexistro Mercantil (BORME)

Se se comparan estas cifras coas do ano anterior neste mesmo período de xaneiro a maio, cómpre salientar que en 2020 se crearon $11 \mathrm{em}$ presas menos. Nos últimos tres anos, a media mensual de constitución de empresas culturais oscilou entre as 11 de 2018 e as 9,5 de 2019.

Na seguinte táboa pódese apreciar a diferenza no número de empresas rexistradas en Galicia nos meses de marzo e abril de 2020. O número total de empresas creadas na comunidade galega nestes dous meses foi de 440, pero en abril creáronse 96, 248 empresas menos que en marzo. Isto supón unha redución dun 72,1\%.

En canto ás empresas culturais, nestes dous meses creáronse 18, 16 en marzo e 2 en abril; a diferenza porcentual de redución entre os dous meses é, polo tanto, superior ao total de empresas, concretamente dun $87,5 \%$.

Número de empresas creadas en Galicia (marzo-abril 2020)

\begin{tabular}{lrrrr} 
& Marzo & Abril & Diferenza & \% de redución \\
\hline Total empresas en Galicia & 344 & 96 & 248 & $-72,1 \%$ \\
Empresas culturais & 16 & 2 & 14 & $-87,5 \%$ \\
\hline \multicolumn{4}{l}{ Fonte: IGE. Explotación do Boletín Oficial do Rexistro Mercantil (BORME) }
\end{tabular}




\section{Comercio exterior e intracomunitario de produtos culturais}

Esta estatística procede dunha explotación elaborada polo IGE a partir dos ficheiros facilitados polo Departamento de Aduanas da Agencia Estatal de Administración Tributaria. Compre ter en conta que o impacto negativo se reduce á segunda quincena de marzo. Dadas as limitacións metodolóxicas que existen neste ámbito, úsanse as clasificacións TARIC (Arancel Integrado das Comunidades Europeas), concretamente cinco epígrafes:

37 Produtos fotográficos ou cinematográficos.

49 Produtos editoriais, da prensa ou doutras industrias gráficas; textos manuscritos ou mecanografados e planos.

85 Máquinas, aparellos e material eléctrico e as súas partes; aparellos para a gravación ou reprodución de son, aparellos para a gravación.

92 Instrumentos de música; partes e accesorios destes instrumentos.

97 Obxectos de arte, de colección ou de antigüidade.

Os resultados provisionais para os tres primeiros meses de 2020 indican que en Galicia se importaron máis produtos culturais dos que se exportaron, unha tendencia que é habitual. Outro dato salientable é que foi nas provincias da Coruña e Pontevedra nas que se produciron máis importacións e exportacións de produtos culturais. Durante o mes de febreiro realizáronse máis exportacións mentres que en xaneiro foron maiores as importacións de produtos fotográficos ou cinematográficos e as de produtos editoriais. A evolución é a que segue: 


\section{Evolución das importacións e exportacións de produtos culturais (xaneiro-marzo 2020)}

$80.000,0$

$60.000,0$

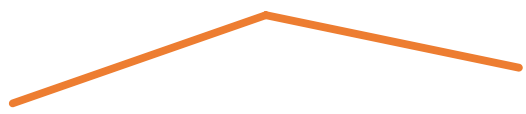

$40.000,0$

$20.000,0$

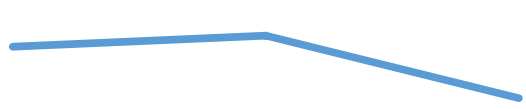

0,0

2020/Xaneiro 2020/Febreiro 2020/Marzo

Exportacións

Fonte: Elaboración IGE a partir dos ficheiros facilitados polo Departamento de Aduanas da Agencia Estatal de Administración Tributaria

Como se pode comprobar, no mes de marzo reduciuse de maneira sensible a actividade exterior, sobre todo as exportacións de produtos culturais. Ao comparar a variación total entre febreiro e marzo co total obtense a seguinte táboa:

Taxas de variación do comercio exterior entre febreiro e marzo de 2020

\begin{tabular}{lr} 
& Diferenza \\
\hline Exportacións de produtos culturais & $-39,4 \%$ \\
Exportacións totais & $-23,9 \%$ \\
Importacións de produtos culturais & $-16,9 \%$ \\
Importacións totais & $-15,3 \%$ \\
\hline
\end{tabular}

Fonte: Elaboración IGE a partir dos ficheiros facilitados polo Departamento de Aduanas da Agencia Estatal de Administración Tributaria

A realidade indica que o comercio exterior da cultura, sobre todo a exportación, viuse máis afectado que o conxunto da actividade galega.

\section{Índice de prezos de consumo}

O Índice de Prezos de Consumo de produtos relacionados co ocio e a cultura en Galicia nos primeiros catro meses de 2020 sitúase 4,5 puntos por debaixo do índice xeral de prezos (99,2 fronte a 103,7), un feito similar ao que acontece no conxunto do Estado, cunha diferenza algo inferior de 3,4 puntos. As taxas de variación indican que no total do cuadrimestre os prezos descenderon de xeito global tanto en Galicia como en España, pero 
non sucedeu así no último mes de estudo. Ao comparar a taxa de variación do índice do último mes de abril respecto ao mes de marzo, obsérvase unha suba de 0,6 puntos nos produtos culturais e de 0,3 no total de produtos, un comportamento moi semellante ao que sucede no conxunto do Estado, cun ascenso de 0,8 nos produtos culturais e de 0,3 na xeneralidade. Na seguinte táboa comparativa amósanse estes datos.

\section{Índice e taxas de variación de prezos de consumo (IPC) base 2016. Índice xeral e por grupos ECOICOP. Primeiro cuadrimestre 2020}

\begin{tabular}{|c|c|c|c|c|c|}
\hline \multicolumn{6}{|c|}{ ctactimestre 2020} \\
\hline & & Xaneiro & Febreiro & Marzo & Abri \\
\hline & \multicolumn{5}{|l|}{ España } \\
\hline \multirow{3}{*}{ Xeral } & Índice & 104,202 & 104,078 & 103,679 & 103,992 \\
\hline & Variación sobre o mes anterior (\%) & $-1,0$ & $-0,1$ & $-0,4$ & 0,3 \\
\hline & Variación no que vai de ano (\%) & $-1,0$ & $-1,1$ & $-1,5$ & $-1,2$ \\
\hline \multirow{3}{*}{$\begin{array}{l}\text { Ocio e } \\
\text { cultura }\end{array}$} & Índice & 99,077 & 99,874 & 99,73 & 100,57 \\
\hline & Variación sobre o mes anterior (\%) & $-2,1$ & 0,8 & $-0,1$ & 0,8 \\
\hline & Variación no que vai de ano (\%) & $-2,1$ & $-1,3$ & $-1,4$ & $-0,6$ \\
\hline & Galicia & & & & \\
\hline \multirow{3}{*}{ Xeral } & Índice & 104,249 & 103,97 & 103,441 & 103,748 \\
\hline & Variación sobre o mes anterior (\%) & $-1,1$ & $-0,3$ & $-0,5$ & 0,3 \\
\hline & Variación no que vai de ano (\%) & $-1,1$ & $-1,3$ & $-1,8$ & $-1,5$ \\
\hline \multirow{3}{*}{$\begin{array}{l}\text { Ocio e } \\
\text { cultura }\end{array}$} & Índice & 98,13 & 98,835 & 98,651 & 99,219 \\
\hline & Variación sobre o mes anterior (\%) & $-1,7$ & 0,7 & $-0,2$ & 0,6 \\
\hline & Variación no que vai de ano (\%) & $-1,7$ & $-1,0$ & $-1,2$ & $-0,6$ \\
\hline
\end{tabular}

Fonte: IGE. Instituto Galego de Estatística. (INE. Índice de precios de consumo. Extraído de http://www.ine.es)

A análise do Índice de Prezos de Consumo por subgrupos dentro do eido cultural ofrece a seguinte información para Galicia. Algúns prezos subiron lixeiramente no primeiro cuadrimestre do ano 2020, especialmente os que teñen que ver con outros grandes bens duradeiros para lecer e cultura, que experimentan un leve ascenso ao final destes primeiros catro meses $(0,1)$ e despuntan no último mes de abril respecto ao mes anterior, cunha taxa de variación de 1,4 puntos. Prensa, libros e artigos de papelaría son outros dos produtos que soben lixeiramente, 0,4 puntos no total do cuadrimestre e 0,2 no último mes de abril. Os servizos recreativos, deportivos e culturais encarécense de xeito pouco significativo no último mes de estudo $(0,2)$, mentres que se manteñen estables no total do cuadrimestre. O único produto cultural que baixa de prezo é o relacionado con equipos audiovisuais, fotográficos e de procesamento de información, 
cun descenso de 1,6 puntos entre xaneiro e abril e unha taxa de variación no último mes de $-0,7$.

O comportamento dos prezos no total do Estado é moi similar, a excepción do produto "Outros grandes bens duradeiros para lecer e cultura”, que, como se indicou con anterioridade, é o que experimenta a maior suba na comunidade galega, mentres que no total España baixa en 0,5 puntos entre os meses de xaneiro e abril, cunha taxa de variación no último mes respecto ao anterior de 0,1 puntos, tal e como se pode comprobar na táboa que vai a continuación.

DOCUMENTOS DE TRABALLO CCG
Índice e taxas de variación de prezos de consumo (IPC) base 2016. Índices de subgrupos. Primeiro cuadrimestre 2020

\begin{tabular}{|c|c|c|c|c|c|}
\hline & & Xaneiro & Febreiro & Marzo & Abril \\
\hline \multicolumn{6}{|l|}{ España } \\
\hline \multirow{4}{*}{$\begin{array}{l}\text { Equipos audiovisuais, } \\
\text { fotográficos e de } \\
\text { procesamento de } \\
\text { información }\end{array}$} & Índice & 85,272 & 84,696 & 84,448 & 84,163 \\
\hline & $\begin{array}{l}\text { Variación sobre o } \\
\text { mes anterior (\%) }\end{array}$ & $-0,3$ & $-0,7$ & $-0,3$ & $-0,3$ \\
\hline & Variación no que vai & & & & \\
\hline & de ano $(\%)$ & $-0,3$ & $-1,0$ & $-1,2$ & $-1,6$ \\
\hline \multirow{4}{*}{$\begin{array}{l}\text { Outros grandes bens } \\
\text { duradeiros para lecer } \\
\text { e cultura }\end{array}$} & Índice & 98,764 & 98,046 & 97,907 & 97,848 \\
\hline & $\begin{array}{l}\text { Variación sobre o } \\
\text { mes anterior }(\%)\end{array}$ & 0,4 & $-0,7$ & $-0,1$ & $-0,1$ \\
\hline & $\begin{array}{l}\text { Variación no que vai } \\
\text { de ano (\%) }\end{array}$ & 0,4 & $-0,3$ & $-0,4$ & $-0,5$ \\
\hline & Índice & 101,386 & 101,693 & 102,487 & 102,527 \\
\hline \multirow[t]{2}{*}{$\begin{array}{l}\text { Servizos recreativos, } \\
\text { deportivos e culturais }\end{array}$} & $\begin{array}{l}\text { Variación sobre o } \\
\text { mes anterior (\%) }\end{array}$ & $-0,3$ & 0,3 & 0,8 & 0,0 \\
\hline & $\begin{array}{l}\text { Variación no que vai } \\
\text { de ano (\%) }\end{array}$ & $-0,3$ & 0,0 & 0,7 & 0,8 \\
\hline \multirow{3}{*}{$\begin{array}{l}\text { Prensa, libros e arti- } \\
\text { gos de papelaría }\end{array}$} & Índice & 107,346 & 107,137 & 107,016 & 107,294 \\
\hline & $\begin{array}{l}\text { Variación sobre o } \\
\text { mes anterior (\%) }\end{array}$ & 0,5 & $-0,2$ & $-0,1$ & 0,3 \\
\hline & $\begin{array}{l}\text { Variación no que vai } \\
\text { de ano (\%) }\end{array}$ & 0,5 & 0,3 & 0,2 & 0,4 \\
\hline \multicolumn{6}{|l|}{ Galicia } \\
\hline \multirow{3}{*}{$\begin{array}{l}\text { Equipos audiovisuais, } \\
\text { fotográficos e de } \\
\text { procesamento de } \\
\text { información }\end{array}$} & Índice & 86,206 & 85,786 & 85,908 & 85,338 \\
\hline & $\begin{array}{l}\text { Variación sobre o } \\
\text { mes anterior (\%) }\end{array}$ & $-0,6$ & $-0,5$ & 0,1 & $-0,7$ \\
\hline & $\begin{array}{l}\text { Variación no que vai } \\
\text { de ano (\%) }\end{array}$ & $-0,6$ & $-0,1$ & $-0,9$ & $-1,6$ \\
\hline \multirow{3}{*}{$\begin{array}{l}\text { Outros grandes bens } \\
\text { duradeiros para lecer } \\
\text { e cultura }\end{array}$} & Índice & 95,109 & 95,109 & 95,254 & 96,587 \\
\hline & $\begin{array}{l}\text { Variación sobre o } \\
\text { mes anterior (\%) }\end{array}$ & $-1,4$ & 0,0 & 0,2 & 1,4 \\
\hline & $\begin{array}{l}\text { Variación no que vai } \\
\text { de ano }(\%)\end{array}$ & $-1,4$ & $-1,4$ & $-1,3$ & 0,1 \\
\hline
\end{tabular}




$\begin{array}{lrrrr}\text { Índice } & 100,888 & 101,188 & 101,353 & 101,394 \\ \begin{array}{l}\text { Variación sobre o } \\ \text { mes anterior (\%) }\end{array} & -0,3 & 0,3 & 0,2 & 0,0 \\ \begin{array}{l}\text { Variación no que vai } \\ \text { de ano (\%) }\end{array} & -0,3 & 0,0 & 0,2 & 0,2 \\ \begin{array}{l}\text { Índice } \\ \begin{array}{l}\text { Variación sobre o } \\ \text { mes anterior (\%) }\end{array}\end{array} & 107,22 & 107,033 & 106,96 & 107,221 \\ \begin{array}{l}\text { Variación no que vai } \\ \text { de ano (\%) }\end{array} & 0,4 & -0,2 & -0,1 & 0,2 \\ & 0,4 & 0,2 & 0,2 & 0,4\end{array}$

os recreativos,

deportivos e culturais

Galego de Estatística. (INE. Índice de precios de consumo. Extraído

Fonte: IGE. Instituto Gal
de http://www.ine.es)

\section{Confianza dos consumidores}

Con relación ás actividades de ocio realizadas pola poboación galega nos últimos tres meses, tales como poder saír cear, a cafetarías, ir o cine e ao teatro, obsérvase nos datos o efecto da crise sanitaria e da declaración no mes de marzo do estado de alarma. Mentres que no último trimestre de 2019 estas prácticas foron posibles para un $62,8 \%$ dos fogares, nos tres primeiros meses de 2020 a porcentaxe baixou un 1,2\%. Este descenso acentúase aínda máis se se compara co primeiro trimestre de 2018, 2,6\% menos, como se pode ver na seguinte gráfica.

\section{Fogares que puideron saír cear, a cafetarías, ir ao cine e ao teatro nos últimos tres meses en Galicia (datos trimestrais)}

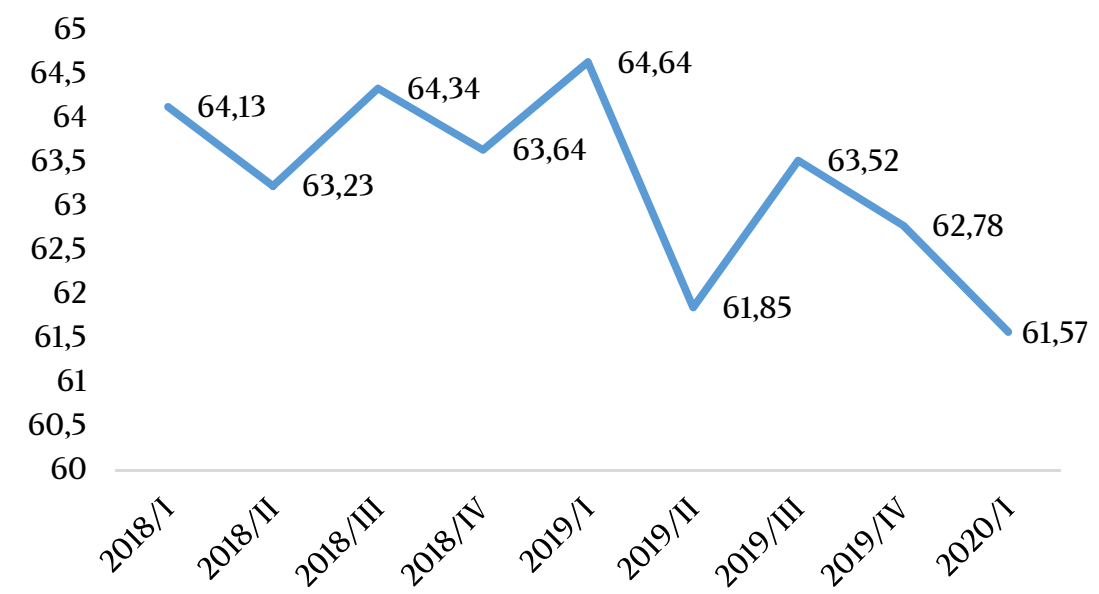

IGE. Enquisa conxuntural a fogares

Os plans de lecer dos fogares galegos de cara ao futuro tamén se ven influídos pola actual situación. Mentres que no último trimestre do 
pasado ano 2019 un 63,3\% pensaba saír cear, a cafetarías ou ir ao cine e ao teatro, no primeiro trimestre de 2020 non chega ao 58\%, isto é, un 5,5\% de fogares menos. Trátase do índice porcentual máis baixo dende o primeiro trimestre de 2018, como se constata a continuación na gráfica.

Fogares que teñen pensado poder saír cear, a cafetarías, ir ao cine ou ir ao teatro nos próximos tres meses en Galicia (datos trimestrais)

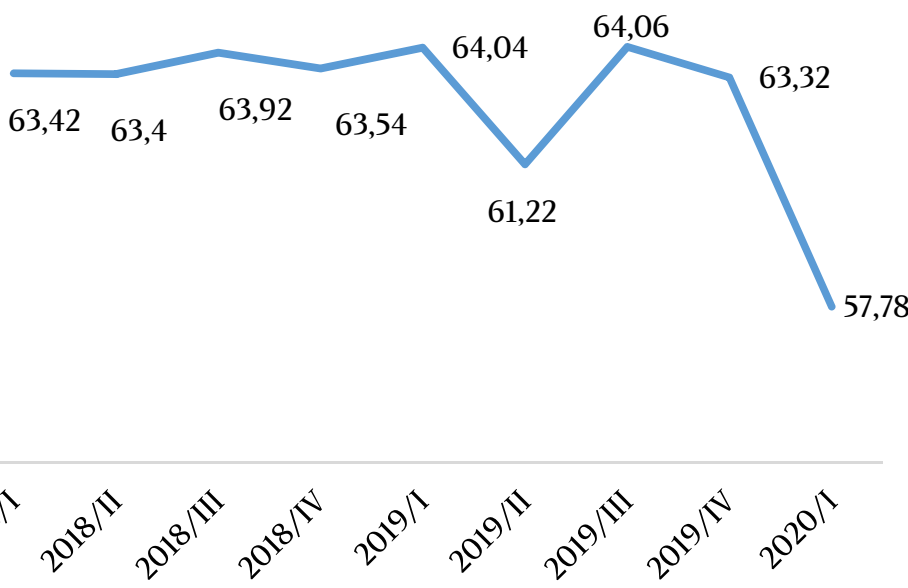

IGE. Enquisa conxuntural a fogares

\section{Emprego cultural na EPA}

Neste apartado ofrécese información relativa ao emprego cultural obtida a partir dunha explotación específica para determinadas actividades económicas e ocupacións do ámbito cultural realizada para o Ministerio de Cultura y Deporte da Encuesta de Población Activa, operación estatística pertencente ao Plan Estatístico Nacional do Instituto Nacional de Estadística.

Os datos que se recollen aquí refírense ao emprego cultural rexistrado no conxunto de España e das comunidades autónomas no cuarto trimestre de 2019 e o primeiro de 2020.

A declaración do estado de alarma tivo importantes repercusións sobre a EPA do primeiro trimestre de 2020, tanto na realización de entrevistas como nas variables medidas. Aínda que os efectos da COVID-19 só se manifestaron desde a semana 11 das 13 de referencia deste trimestre, víronse afectados varios aspectos da enquisa.

No conxunto de España o emprego cultural descendeu en 4.700 traballadores mentres que en Galicia aumentou en 1.000 traballadores con 
respecto ao último trimestre de 2019. Pero hai que ter en conta que estas cifras non inclúen os afectados por un ERTE con suspensión de emprego, que, segundo a metodoloxía da EPA, se consideran ocupados mentres esa suspensión sexa inferior a tres meses.

O emprego cultural en Galicia representa neste trimestre un 3,3\% do total do emprego, o que supón 3 décimas menos que no conxunto do Estado. Con respecto ao cuarto trimestre de 2019, o emprego cultural en Galicia aumentou nun punto porcentual.

\section{Emprego cultural por comunidades autónomas}

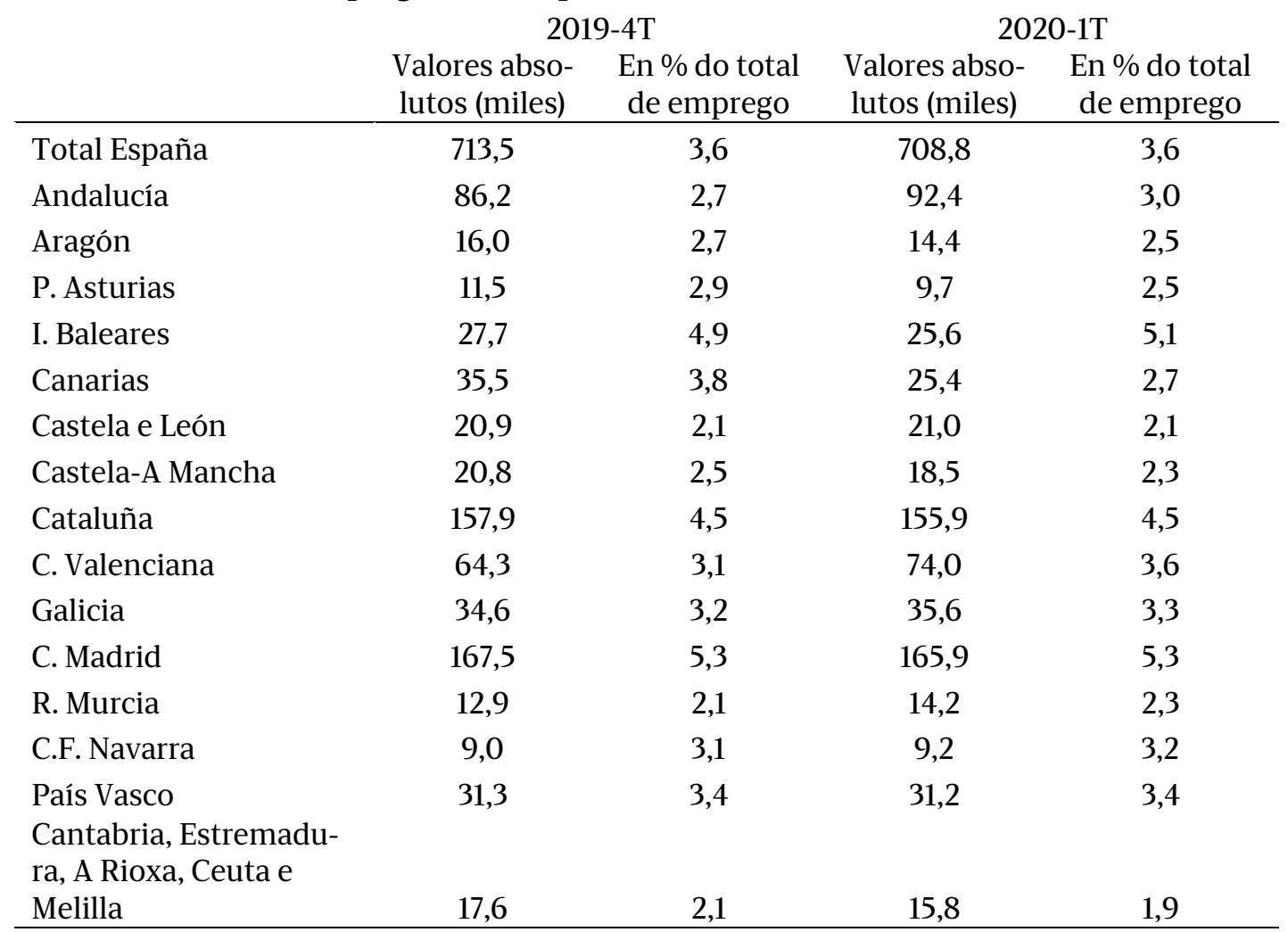

Fonte: MCUD. Explotación de Encuesta de Población Activa no ámbito cultural. INE. Encuesta de Población Activa

O emprego descende en case todas as comunidades autónomas agás en Andalucía, Castela e León, Comunidade Valenciana, Murcia, Navarra e País Vasco, ademais de Galicia. Navarra é a comunidade na que se rexistrou a cifra máis baixa de emprego cultural e a Comunidade de Madrid a que ten a cifra máis alta. 
Na seguinte gráfica obsérvanse datos sobre a variación trimestral do emprego cultural entre o primeiro trimestre de 2020 e o cuarto trimestre de 2019.

\section{Variación trimestral do emprego cultural (en miles de persoas)}

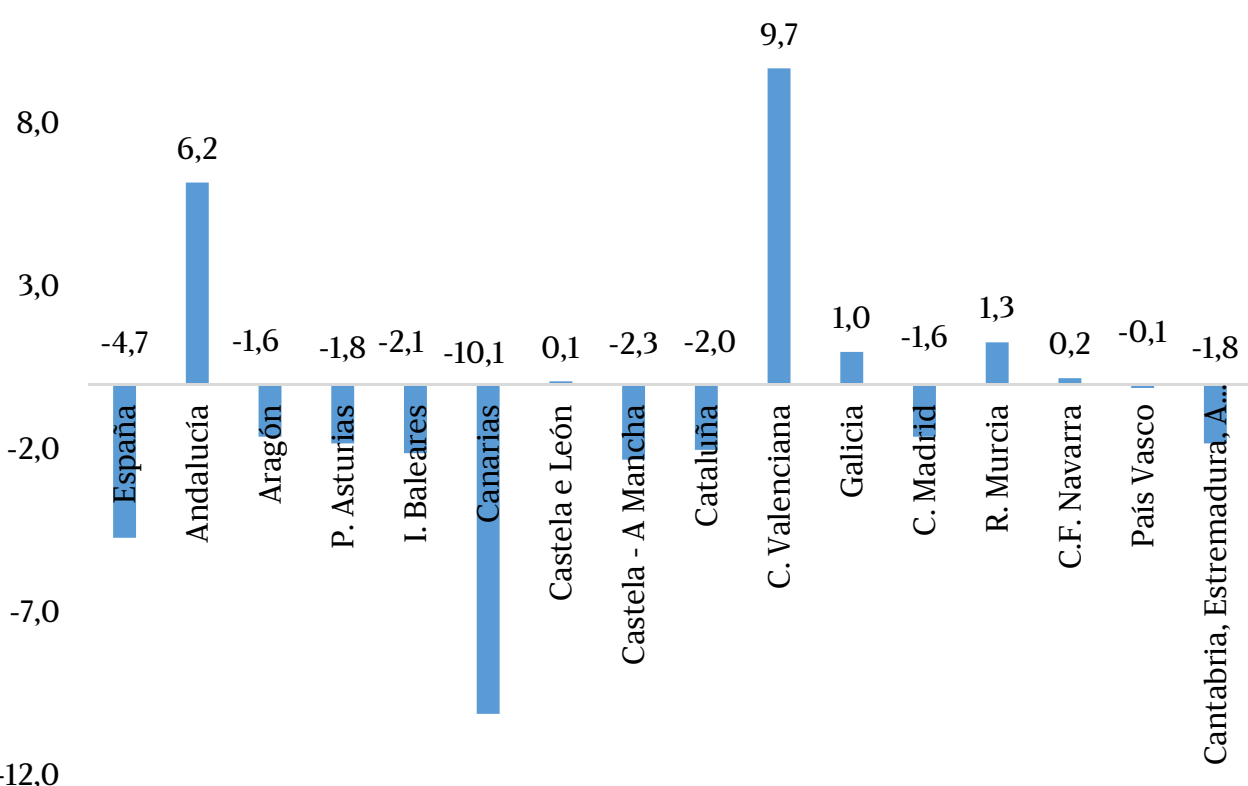

Fonte: MCUD. Explotación de Encuesta de Población Activa no ámbito cultural. INE. Encuesta de Población Activa

\section{Afiliacións á Seguridade Social}

Galicia rexistra a finais de maio de 2020 unha cifra de 15.281 persoas afiliadas á Seguridade Social nas principais actividades culturais, o que representa o 1,5\% do total de afiliacións de todos os sectores. Os datos reflicten unha baixada no número de afiliacións de febreiro a abril e unha repunta en maio.

\begin{tabular}{lrrrrr}
\multicolumn{6}{c}{ Afiliacións totais e no eido cultural á Seguridade Social en Galicia } \\
& (último día do mes) & & & \\
& Xaneiro & Febreiro & Marzo & Abril & Maio \\
\hline Total afiliacións & 1.003 .591 & 1.012 .422 & 980.069 & 969.784 & 979.472 \\
Total afiliacións cultura & 15.787 & 15.881 & 15.013 & 14.879 & 15.281 \\
\hline
\end{tabular}

Fonte: IGE. Instituto Galego de Estatística

Entre o último día do mes de febreiro (antes de iniciarse o estado de alarma) e o último día de abril constátase a diminución máis severa, 
42.638 persoas afiliadas menos no cómputo xeral e 1.002 no eido cultural. Isto significa que o sector cultural experimentou un descenso dun 6,3\% no número de afiliacións, 2,1 puntos porcentuais máis que no total de actividades, que minguaron un -4,2\%. Tamén é certo que o aumento das afiliacións en maio é maior na cultura $(+2,7 \%)$ que no conxunto do mercado laboral (+1\%).

Un 73,8\% das afiliacións do eido cultural corresponden a catro ramas, repartidas do seguinte xeito: $23,9 \%$ a publicidade e estudos de mercado, 21,1\% a artes gráficas e reprodución de soportes gravados, 14,8\% a actividades de creación, artísticas e de espectáculos e 14,1\% a edición.

Ao analizar polo miúdo o número de afiliacións á Seguridade Social segundo as ramas da CNAE 2009 entre o último día do mes de febreiro e o último de maio, compróbase que todos os sectores de actividades culturais experimentaron un descenso do número de afiliacións, coa excepción do de publicidade e estudos de mercado, que creceu un 2,1\%. As ramas que soportaron unha maior baixada e que semellan as máis afectadas pola crise sanitaria son as relacionada coas actividades de creación, artísticas e de espectáculos (-10,4\%), seguidas das cinematográficas, de vídeo e de programas de televisión, gravación de son e edición musical, que sufriron un decrecemento dun 10\%. A maior distancia atópanse o resto de ramas, tal como se detalla na táboa que se mostra a continuación. 
Afiliacións á Seguridade Social o último día do mes, segundo réximes e ramas da CNAE 2009 en Galicia. Primeiro cuadrimestre 2020

\begin{tabular}{|c|c|c|c|c|c|}
\hline & Xaneiro & Febreiro & Marzo & Abril & Maio \\
\hline $\begin{array}{l}18 \text { Artes gráficas e reprodución de soportes gra- } \\
\text { vados }\end{array}$ & 3.232 & 3.320 & 3.240 & 3.217 & 3.222 \\
\hline 58 Edición & 2.200 & 2.207 & 2.174 & 2.164 & 2.149 \\
\hline $\begin{array}{l}59 \text { Actividades cinematográficas, de vídeo e de } \\
\text { programas de televisión, gravación de son e } \\
\text { edición musical }\end{array}$ & 1.386 & 1.439 & 1.221 & 1.175 & 1.294 \\
\hline $\begin{array}{l}60 \text { Actividades de programación e emisión de } \\
\text { radio e televisión }\end{array}$ & 1.402 & 1.398 & 1.372 & 1.368 & 1.361 \\
\hline 63 Servizos de información & 927 & 933 & 897 & 890 & 887 \\
\hline 73 Publicidade e estudos de mercado & 3.578 & 3.587 & 3.355 & 3.374 & 3.663 \\
\hline $\begin{array}{l}90 \text { Actividades de creación, artísticas e espectá- } \\
\text { culos }\end{array}$ & 2.584 & 2.516 & 2.291 & 2.232 & 2.255 \\
\hline $\begin{array}{l}91 \text { Actividades de bibliotecas, arquivos, museos } \\
\text { e outras actividades culturais }\end{array}$ & 478 & 481 & 463 & 459 & 450 \\
\hline
\end{tabular}

Fonte: IGE. Instituto Galego de Estatística

Ao establecer unha comparativa da evolución das afiliacións á Seguridade Social entre os sectores económicos máis relevantes, ponse de manifesto que o sector cultural é o máis prexudicado de todos, cun decrecemento nas afiliacións no momento máis crítico, entre finais de febreiro e finais de abril, dun 6,3\%, seguido do da construción cun 6,2\%. O sector servizos tamén se viu afectado cun descenso dun 4,5\%. A seguinte táboa detalla esta evolución.

\begin{tabular}{|c|c|c|c|c|}
\hline \multicolumn{5}{|c|}{$\begin{array}{l}\text { Evolución das afiliacións á Seguridade Social nas principais actividades econór } \\
\text { segundo a CNAE } 2009 \text { en Galicia } \\
\text { (último día de febreiro e o último día de abril de 2020) }\end{array}$} \\
\hline & Febreiro & Marzo & Abril & Evolución \\
\hline Cultura & 15.881 & 15.013 & 14.879 & $-6,3$ \\
\hline Agricultura e pesca & 58.097 & 57.771 & 57.449 & $-1,1$ \\
\hline Industria & 146.492 & 143.473 & 141.779 & $-3,2$ \\
\hline Construción & 76.523 & 72.246 & 71.749 & $-6,2$ \\
\hline Servizos & 728.193 & 703.386 & 695.614 & $-4,5$ \\
\hline Non tipificados & 3.117 & 3.193 & 3.193 & \\
\hline
\end{tabular}

Fonte: IGE. Instituto Galego de Estatística 
DOCUMENTOS DE TRABALLO

DOCUMENTOS DE TRABALLO

\section{Expedientes de regulación temporal de emprego}

A seguinte táboa mostra as cifras do número de ERTE solicitados por empresas do sector cultural en 2020. Así, pódese ver que un 11,6\% das empresas do sector cultural4, é dicir, un total de 667, solicitaron un ERTE. O sector no que se presentaron máis ERTE foi o de artes gráficas e reprodución de soportes gravados, que ascende a un $27,2 \%$ das empresas activas neste sector. $\mathrm{O}$ seguinte sector con maior número de ERTE foi o de actividades de creación, artísticas e espectáculos, cun total de 152 ERTE. No extremo oposto, o sector no que se presentaron menos ERTE foi o de actividades de programación e emisión de radio e televisión, cun total de 17, pero proporcionalmente foron as empresas deste sector as segundas máis afectadas, xa que a cuarta parte delas en Galicia solicitaron un expediente de regulación deste tipo.

\section{No de ERTE solicitados por empresas activas do sector cultural}

\begin{tabular}{|c|c|c|c|}
\hline Actividade & $\begin{array}{l}\text { Empresas } \\
\text { activas }\end{array}$ & ERTE & $\begin{array}{l}\text { \% ERTE por } \\
\text { empresa }\end{array}$ \\
\hline $\begin{array}{l}\text { 18. Artes gráficas e reprodución de soportes } \\
\text { gravados }\end{array}$ & 895 & 243 & $27,2 \%$ \\
\hline 58. Edición & 369 & 40 & $10,8 \%$ \\
\hline $\begin{array}{l}\text { 59. Actividades cinematográficas, de vídeo e de } \\
\text { programas de televisión, gravación de son e } \\
\text { edición musical }\end{array}$ & 407 & 59 & $14,5 \%$ \\
\hline $\begin{array}{l}\text { 60. Actividades de programación e emisión de } \\
\text { radio e televisión }\end{array}$ & 68 & 17 & $25,0 \%$ \\
\hline 73. Publicidade e estudos de mercado & 1.653 & 124 & $7,5 \%$ \\
\hline $\begin{array}{l}\text { 90. Actividades de creación, artísticas e espectá- } \\
\text { culos }\end{array}$ & 2.158 & 152 & $7,0 \%$ \\
\hline $\begin{array}{l}\text { 91. Actividades de bibliotecas, arquivos, museos } \\
\text { e outras actividades culturais }\end{array}$ & 214 & 32 & $15,0 \%$ \\
\hline TOTAL & 5.764 & 667 & $11,6 \%$ \\
\hline
\end{tabular}

Na seguinte táboa preséntanse datos sobre o número de persoas traballadoras empregadas en empresas que solicitaron un ERTE segundo os distintas ramas culturais. No conxunto do sector cultural, 4.010 persoas traballan en empresas que solicitaron un ERTE, cifra que representa un 28,7\% das persoas afiliadas á Seguridade Social en abril de 2020 nestes sectores. O sector máis afectado foi o de artes gráficas e reprodución de

\footnotetext{
${ }^{4}$ Tómanse como referencias as empresas activas nos últimos datos dispoñibles no Directorio de empresas e unidades locais do Instituto Galego de Estatística.
} 
soportes gravados, no que un $48,6 \%$ das persoas empregadas dependían de empresas que solicitaron un ERTE. O segundo sector máis afectado foi o das actividades de creación, artísticas e espectáculos, con 777 persoas que traballan en empresas que solicitaron un ERTE, cifra que representa un 34,8\% das afiliacións á Seguridade Social neste sector en abril de 2020. Proporcionalmente, as actividades de programación e emisión de radio e televisión foron as que se viron menos afectadas, xa que só un 4,7\% das persoas neste sector traballan en empresas que solicitaron un ERTE.

\section{Porcentaxe de persoas traballadoras dependentes de empresas que solicitaron ER- TE segundo as afiliacións á Seguridade Social}

CNAE (sector cultural)
№ de afiliados á Seguridade Social (abril 2020)

\section{Persoas traba- lladoras}

$\%$ de ERTE por afiliacións

\begin{tabular}{|c|c|c|c|}
\hline $\begin{array}{l}\text { 18. Artes gráficas e reprodución de } \\
\text { soportes gravados }\end{array}$ & 3.217 & 1.565 & $48,6 \%$ \\
\hline 58. Edición & 2.164 & 687 & $31,7 \%$ \\
\hline $\begin{array}{l}\text { 59. Actividades cinematográficas, } \\
\text { de vídeo e de programas de televi- } \\
\text { sión, gravación de son e edición } \\
\text { musical }\end{array}$ & 1.175 & 274 & $23,3 \%$ \\
\hline $\begin{array}{l}\text { 60. Actividades de programación e } \\
\text { emisión de radio e televisión }\end{array}$ & 1.368 & 64 & $4,7 \%$ \\
\hline $\begin{array}{l}\text { 73. Publicidade e estudos de mer- } \\
\text { cado }\end{array}$ & 3.374 & 585 & $17,3 \%$ \\
\hline $\begin{array}{l}\text { 90. Actividades de creación, artísti- } \\
\text { cas e espectáculos }\end{array}$ & 2.232 & 777 & $34,8 \%$ \\
\hline $\begin{array}{l}\text { 91. Actividades de bibliotecas, ar- } \\
\text { quivos, museos e outras activida- } \\
\text { des culturais }\end{array}$ & 459 & 58 & $12,6 \%$ \\
\hline TOTAL & 13.989 & 4.010 & $28,7 \%$ \\
\hline
\end{tabular}

Fonte: Elaboración propia a partir de Consellería de Economía, Emprego e Industria e IGE

Para poder comparar os datos hoxe en día, a Xunta ten contabilizadas en Galicia un total de 36.683 solicitudes de ERTE que afectan a 211.878 traballadores, o cal significa o 14,8\% das empresas activas e o 21,6\% das persoas afiliadas á Seguridade Social do mes de abril. Isto quere dicir que hai en proporción un número maior de empresas afectadas e, en contraste, un menor de persoas no conxunto de Galicia con respecto ao ámbito cultural. 
Estes datos non significan que todas estas persoas estean actualmente acollidas a un ERTE. Ademais, pódese dar o caso de empresas que xa o teñan levantado parcial ou totalmente, información que é competencia do Servizo Público de Emprego Estatal (SEPE).

\section{Contabilidade trimestral}

As contas económicas trimestrais de Galicia constitúen unha estatística de síntese de carácter conxuntural que ten como obxectivo proporcionar unha descrición cuantitativa do conxunto da actividade económica galega mediante a elaboración dun cadro macroeconómico que ofrece o ritmo de crecemento do PIB galego e das súas compoñentes.

De acordo cos datos que se proporcionan na seguinte táboa, no primeiro trimestre de 2020, o PIB a prezos de mercado reduciuse en 4,9 puntos con respecto ao trimestre anterior.

Polo outro lado, ofrécense datos do PIB a prezos de mercado pola vía da oferta, o VEB, nos catro sectores principais:

- Agricultura, gandaría, silvicultura e pesca

- Industria

- Construción

- Servizos

Estrutura do Produto Interior Bruto (PIB) a prezos de mercado, pola vía da oferta. Datos corrixidos de estacionalidade e calendario (base 2015). Galicia

\begin{tabular}{lr} 
Taxa de variación trimestre anterior & Datos corrixidos de estacionalidade \\
\hline PIBpm & $-4,9$ \\
Oferta (VEB) & $-0,9$ \\
Agricultura, gandaría, silvicultura e pesca & $-1,2$ \\
Industria & $-2,1$ \\
Industria manufactureira & $-8,6$ \\
Construción & $-5,2$ \\
Servizos & $-11,4$ \\
Comercio, transporte e hostalaría & 0,1 \\
Información e comunicacións & -0.2 \\
Actividades financeiras e de seguros & $-0,6$
\end{tabular}


Administración pública, sanidade e edu- $\quad 0,1$

cación

Actividades artísticas, recreativas e outros $\quad-10,0$

servizos

Fonte: IGE. Contas económicas trimestrais. Revisión estatística 2019

Dentro da desagregación que permite esta operación estatística, pódese comprobar que, entre o conxunto de actividades, as artísticas e recreativas (que inclúen actividades de creación e espectáculos) sofren a segunda caída máis importante (-10), só por detrás do comercio, transporte e hostalaría $(-11,4)$.

No caso do grupo de actividade de información e comunicación (que experimentan un incremento do 0,1\%), atópanse, xunto coa edición, as actividades cinematográficas, de vídeo e de programas de televisión, as actividades informáticas e de telecomunicacións. A evolución nas últimas contas anuais das que se dispón indican esta variación:

\section{Contas de produción e explotación por ramas de actividade. Revisión Estatística} 2019. Serie 2000-2017. Miles de euros. Prezos correntes

\begin{tabular}{|c|c|c|c|}
\hline & 2016 & 2017 & Diferenza \\
\hline \multicolumn{4}{|l|}{ Conta de explotación. Recursos } \\
\hline \multicolumn{4}{|l|}{ B.1 Valor Engadido Bruto } \\
\hline R58 Edición & 81.363 & 79.656 & $-2,1 \%$ \\
\hline $\begin{array}{l}\text { R59_60 Actividades cinematográficas, de vídeo e } \\
\text { televisión, gravación de son e edición musical; } \\
\text { actividades de programación e emisión de radio e } \\
\text { televisión }\end{array}$ & 145.811 & 144.905 & $-0,6 \%$ \\
\hline R61 Telecomunicacións & 872.252 & 928.770 & $6,5 \%$ \\
\hline $\begin{array}{l}\text { R62_63 Programación, consultaría e outras acti- } \\
\text { vidades relacionadas coa informática; servizos de } \\
\text { información }\end{array}$ & 399.850 & 427.295 & $6,9 \%$ \\
\hline Total & 52.146 .418 & 53.792 .931 & $3,2 \%$ \\
\hline
\end{tabular}

IGE. Contas económicas de Galicia. Revisión Estatística 2019

Os datos son provisionais

Tal e como se pode apreciar, nun momento expansivo da economía, as actividades culturais desa sección perderon peso, mentres que as 
actividades de telecomunicación e informática tiveron unha evolución moito máis positiva que o conxunto da economía.

Isto parece indicar que a evolución desa sección na actualidade é tamén peor no caso das actividades de edición e actividades cinematográficas, de vídeo e de programas de televisión, aínda que probablemente mellor que nas actividades artísticas e recreativas.

\section{Estimación da evolución}

O Foro Económico de Galicia 5 elaborou unha estimación de impacto económico baseado en dous escenarios posibles, un confinamento moderado ou estrito, segundo como evolucione a pandemia. Nese documento sinalan que "a economía galega amosa que a contracción da actividade económica para o ano 2020 oscila entre o 8,5\% do PIB no primeiro escenario e o 12,7\% no segundo". Na desagregación por grupos de actividade indican que a rama de información e comunicacións (onde se inclúe a edición, as actividades cinematográficas, de vídeo e de programas de televisión, gravación de son e edición musical, actividades de programación e emisión de radio e televisión e os servizos de información) sufrirá un impacto baixo en calquera dos dous escenarios posibles (moderado ou estrito). No grupo de actividades artísticas, recreativas e de entretemento, o impacto estimado é total ou moi alto nos dous escenarios.

Esta situación apunta a que o sector cultural terá diferentes niveis de afectación segundo as actividades de que se trate. Tendo en conta o dito no anterior apartado e que a previsión tamén se dá para o total da sección de información e comunicación, a estimación da evolución é a que segue:

- Prevese un impacto similar ao do conxunto da economía en actividades de edición e nas cinematográficas, de vídeo e de programas de televisión.

- Prevese un impacto máis elevado que o conxunto da economía en actividades artísticas e de espectáculos.

\footnotetext{
${ }^{5}$ https://api.foroeconomicodegalicia.es/uploads/FEG/originals/93dc77d0-232b-47c4895f-595bed92429f.pdf
} 
Se se toma o conxunto de actividades culturais, a estimación tamén indicaría que estas sufrirían un impacto máis elevado que o conxunto da economía, independentemente do escenario previsto.

\section{Conclusións}

Neste documento de traballo fíxose un repaso de todos os indicadores dispoñibles para o ámbito cultural.

Os datos do Boletín do Rexistro Mercantil indican, como era de esperar, que a creación de empresas sufriu unha baixada moi importante nos últimos meses. Con todo, en abril creáronse dúas empresas culturais, o cal significa un descenso do $84,5 \%$ respecto de marzo. O ritmo de contracción de empresas do total da economía galega tamén se viu afectado, pero sensiblemente menos (-72,1\%).

O comercio exterior tamén se reduciu dunha maneira máis clara na cultura ca no resto de actividades. Experimentaron un descenso acusado as exportacións de produtos culturais, que amosan un retroceso do 39,4\% fronte ao $23,9 \%$ do total entre os meses de febreiro e marzo. As importacións tamén se viron reducidas, pero en menor medida $(-16,9 \%$ os produtos culturais, fronte ao $-15,3 \%$ do total).

No relativo aos prezos, o comportamento foi similar para os produtos culturais e para o conxunto, dado que tiveron unha pequena repunta en abril $(+0,8 \%)$ despois de meses de baixadas, cunha variación no que vai de ano do $-1,2 \%$.

A confianza dos consumidores tamén se ve afectada pola crise da COVID-19, de xeito que só o 57,8\% dos fogares galegos prevé poder saír cear, a cafetarías, ir ao cine ou ir ao teatro nos próximos tres meses, un $5,5 \%$ menos de fogares que o trimestre anterior.

O emprego sufriu tamén un impacto severo. Malia que os datos da EPA ofrecían un escenario positivo nos primeiros tres meses de 2020, as afiliacións á Seguridade Social indican que entre o último día de febreiro e o último dia de abril se perderon 1.002 cotizantes no ámbito cultural, o cal supón unha caída do 6,3\%, 2,1 puntos por riba do total do emprego galego. En maio o emprego recuperouse un pouco. As ramas que soportaron unha maior baixada ata o momento e que semellan as máis afectadas pola crise sanitaria son as relacionadas coas actividades de creación, artísticas e de 
espectáculos (-10,4\%), seguidas das cinematográficas, de vídeo e de programas de televisión, gravación de son e edición musical, que sufriron un decrecemento dun 10\%. O aumento das afiliacións entre abril e maio é maior na cultura $(+2,7 \%)$ que no conxunto da economía $(+1 \%)$.

Pola súa banda, os expedientes de regulación temporal de emprego (ERTE) afectan a 667 empresas culturais, das que dependen 4.010 persoas traballadoras. As actividades máis afectadas en termos absolutos son as relacionadas coas artes gráficas (243 expedientes), seguidas das actividades de creación, artísticas e espectáculos (152 expedientes). Malia que non todas as persoas que traballan nestas empresas teñen que estar necesariamente afectadas polo ERTE e que algúns expedientes poden atoparse parcial ou totalmente levantados, a realidade é que neste momento o $28,7 \%$ dos traballadores da cultura depende dunha empresa que solicitou nalgún momento deste ano un procedemento de regulación temporal. En comparación co conxunto do mercado laboral galego, os ERTE afectaron en proporción a menos empresas da cultura, pero a máis traballadores.

Todos estes datos teñen un reflexo na contabilidade trimestral de Galicia, que, como se sabe, experimentou unha contracción do 4,9\% no seu PIB no primeiro trimestre de 2020. As actividades artísticas e recreativas (que inclúen actividades de creación e espectáculos) sofren unha caída do $10 \%$, a segunda máis importante do conxunto da economía galega, só por detrás do comercio, transporte e hostalaría (-11,4\%). As actividades de edición e as actividades cinematográficas, de vídeo e de programas de televisión son máis difíciles de observar por atoparse agregadas ás actividades informáticas e de telecomunicacións, pero a análise de evolución pasada e os indicadores do mercado laboral apuntan a que teñen unha evolución negativa, aínda que probablemente non tan acusada como a das actividades artísticas e recreativas.

As estimacións de evolución do sector cultural que se ofrecen neste documento están baseadas nas realizadas polo Foro Económico de Galicia, que consideran dous escenarios en función da evolución da pandemia. A contracción do PIB anual galego en 2020 sería do 8,5\% nun escenario menos adverso (confinamento “moderado") e do 12,7\% no peor escenario (confinamento estrito). De acordo coas desagregacións que ofrece esta simulación e os datos observados ao longo deste documento de traballo, pódese afirmar que dentro da cultura haberá un impacto similar ao do 
conxunto da economía nas actividades de edición e as cinematográficas, de vídeo e de programas de televisión e un impacto máis grave que o conxunto da economía para as actividades de creación, artísticas e de espectáculos en calquera dos dous escenarios posibles. 